\title{
Development of a Geodetic Component for the U.S. West Coast Earthquake Early Warning System
}

\author{
by J. R. Murray, B. W. Crowell, R. Grapenthin, K. Hodgkinson, J. 0. \\ Langbein, T. Melbourne, D. Melgar, S. E. Minson, and D. A. Schmidt
}

\begin{abstract}
An earthquake early warning (EEW) system, ShakeAlert, is under development for the West Coast of the United States. This system currently uses the first few seconds of waveforms recorded by seismic instrumentation to rapidly characterize earthquake magnitude, location, and origin time; ShakeAlert recently added a seismic line source algorithm. For large to great earthquakes, magnitudes estimated from the earliest seismic data alone generally saturate. Real-time Global Navigation Satellite System (GNSS) data can directly measure large displacements, enabling accurate magnitude estimates for $M_{\mathrm{w}} 7+$ events, possibly before rupture termination. GNSS-measured displacements also track evolving slip and, alone or in combination with seismic data, constrain finite-fault models. Particularly for large-magnitude, long-rupture events, GNSS-based magnitude and rupture extent estimates can improve updates to predicted shaking and thus alert accuracy. GNSS data processing centers at ShakeAlert partner institutions provide real-time streams to the EEW system, and three geodetic EEW algorithms have been developed through the ShakeAlert collaboration. These algorithms will undergo initial testing within ShakeAlert's computational architecture using a suite of input data that includes simulated real-time displacements from synthetic earthquakes and GNSS recordings from recent earthquakes worldwide. Performance will be evaluated using metrics and standards consistent with those adopted for ShakeAlert overall. This initial assessment will guide method refinement and synthesis of the most successful features into a candidate geodetic algorithm for the ShakeAlert production system. In parallel, improvements to geodetic networks and streamlining approaches to data processing and exchange will ensure robust geodetic data availability in the event of an earthquake.
\end{abstract}

Electronic Supplement: Table listing recent earthquakes for which high sample-rate $(\geq 1 \mathrm{~Hz})$ processed Global Positioning System data and seismic data have been gathered for use in testing geodetic earthquake early warning algorithms and a summary of ground-motion metrics adopted by ShakeAlert, the U.S. West Coast EEW system, for evaluating new or updated components before adoption in the production system, and a schematic diagram of the real-time Global Navigation Satellite Systems data flow for ShakeAlert.

\section{INTRODUCTION}

The West Coast of the continental United States spans two active plate boundaries with varying tectonic styles and faulting behavior. This region includes the major strike-slip faults of the San Andreas system; blind-thrust faults beneath urban areas; and the Cascadia subduction zone where earthquakes occur in the upper crust, downgoing slab, back-arc, and on the subduction interface. Historical events highlight the risks in these regions. As examples of the potential for large ruptures, the San Andreas fault produced the $1906 M_{\mathrm{w}} \sim 7.9$ San Francisco earthquake (Song et al., 2008) and the $1857 M_{\mathrm{w}} \sim 7.7$ Fort Tejon earthquake (Zielke et al., 2012). The Cascadia subduction zone is capable of generating $M_{\mathrm{w}} \sim 9.0$ events, the most recent of which occurred in 1700 (Satake et al., 2003) with estimated average recurrence intervals of $\sim 500$ yrs (Atwater and Hemphill-Haley, 1997; Atwater and Griggs, 2012; Goldfinger et al., 2012).

Earthquake early warning (EEW) systems, which have been implemented in several countries (Minson et al., 2015), including Japan (Hoshiba et al., 2008), Mexico (EspinosaAranda et al., 2009), and Taiwan (Chen et al., 2015), leverage signals recorded during the early stages of an earthquake by sensors near the epicenter to provide advance warning of impending shaking for more distant locations. Efforts to develop a California EEW system began in 2006 and have expanded to include Oregon and Washington in an EEW system named ShakeAlert for the West Coast of the United States. Given $e t$ al. (2014) presented a technical implementation plan for ShakeAlert; a revised version is planned for 2018 (D. D. Given, written comm., 2018). Beta testing of live alert messages since 2012 
in California (Böse et al., 2014) and 2015 in the Pacific northwest, along with release of the California production prototype in 2016 (Kohler et al., 2017), have laid the groundwork for achieving the goal of limited public alerting in 2018. ShakeAlert is a distributed system involving multiple alerting institutions that run the EEW algorithms and several monitoring networks that provide input for these algorithms. The system draws upon existing physical infrastructure and the software and methods used by the Advanced National Seismic System (ANSS) seismic networks (Given et al., 2014).

Ongoing system development includes performance monitoring, modification, and testing of existing algorithms to address deficiencies; standardization of system software using best practices adopted by ShakeAlert partners for code development and documentation; and infrastructure upgrades that improve station coverage and network resiliency to ensure that adequate real-time data are available for the geographic and earthquake magnitude range targeted for issuing alerts. Research and development of new algorithms proceeds in parallel; approaches that bring unique improvements in alert accuracy and timeliness to the overall system will be incorporated in the future.

ShakeAlert currently uses only seismic data from the ANSS to provide input for algorithms that calculate the magnitude, location, and origin time of the ensuing earthquake. Nonetheless, it is well known that earthquake magnitudes calculated by EEW algorithms that use seismic data alone saturate (i.e., are underestimated) for $M_{\mathrm{w}} 7+$ earthquakes (Kuyuk and Allen, 2013); this significantly limits shaking alert accuracy. Real-time geodetic data, in particular displacement estimates from the U.S. Global Positioning System (GPS) and other Global Navigation Satellite Systems (GNSSs) worldwide, provide unique measurements that complement seismic data and are thus indispensable for fully characterizing large earthquakes as they unfold.

This article details the anticipated contribution of real-time GNSS data to ShakeAlert. Real-time, high-rate ( $\geq 1 \mathrm{~Hz})$ GNSS data can resolve displacements exceeding $\sim 1 \mathrm{~cm}$ (horizontal) and $\sim 5 \mathrm{~cm}$ (vertical) (Bock and Melgar, 2016). The amount of time required to accumulate 1 - to $5-\mathrm{cm}$ displacements depends on earthquake source characteristics and source-station spacing. Although more time is required to accumulate GNSSresolvable displacements than to obtain information from the first few seconds of a seismic waveform, the ability of GNSS to directly record large permanent, or static, offsets caused by an earthquake offers significant improvements for EEW by enabling accurate magnitude estimates for large and great earthquakes. Furthermore, real-time GNSS displacements track the evolving rupture extent, locate regions of peak slip, and constrain the fault orientation, all of which contribute to improved ground-motion predictions. Initial analyses demonstrated that geodetically constrained magnitude and source parameter estimates can be obtained quickly enough to provide timely alert updates in the event of large and great earthquakes (e.g., Melgar, Crowell, et al., 2015; Ruhl et al., 2017). We envision that real-time GNSS data will be particularly important to improve shaking alerts for long ruptures of crustal faults such as the San Andreas and for Cascadia megathrust events.
Several algorithms that use real-time GNSS data for EEW purposes have been developed as part of the ShakeAlert project. We outline an evaluation process based on ground-motion metrics to identify the algorithm features that provide unique improvement to ShakeAlert and to integrate these into a geodetic component for the production system. Finally, we highlight network upgrades that would best ensure the availability of real-time GNSS data for ShakeAlert, including strengthening telemetry, reducing points of failure, collocating GNSS and strong-motion stations, and future incorporation of data from low-cost sensors.

\section{THE ANTICIPATED CONTRIBUTION OF REAL-TIME GNSS DATA TO SHAKEALERT}

The current ShakeAlert EEW system uses one seismic pointsource algorithm that consolidates previously developed methods (Böse et al., 2009; Kuyuk et al., 2014) and uses the first few seconds of the $P$ wave recorded by broadband seismometers and accelerometers to estimate origin time, epicentral location, and magnitude of a point source. This information, coupled with ground-motion prediction equations (GMPEs; e.g., Boore and Atkinson, 2008), is used to predict shaking at a user's location. Using the earliest available data and a simple source model enables fast alerts; however, magnitude estimates resulting from seismic point-source EEW algorithms saturate for earthquakes of $M_{\mathrm{w}}>7$ (Kuyuk and Allen, 2013). The static offsets generated by an earthquake scale with the seismic moment of the event, and their observations are critical to fully characterize the earthquake source. However, integration of data from inertial sensors such as accelerometers to obtain displacement generally results in baseline drift caused by rotational motion of the instrument during the earthquake (Boore, 2001). Baseline corrections such as bandpass filtering mitigate drift but bias longer period information, including the static offset, as discussed by Melgar et al. (2013).

In contrast, GNSS data directly measure arbitrarily large static and long-period (>10 s) displacements in a fixed, noninertial reference frame without filtering or integration. Maximum horizontal displacements for an $M_{\mathrm{w}} 7$ crustal strike-slip earthquake derived from magnitude-length scaling (Wells and Coppersmith, 1994) and an elastic dislocation model (Okada, 1985 ) are $\sim 30-50 \mathrm{~cm}$ within $10 \mathrm{~km}$ of the fault trace; $M_{\mathrm{w}} 7$ dip-slip events can have vertical displacements exceeding $50 \mathrm{~cm}$ within $5 \mathrm{~km}$ of the rupture's upper edge. Therefore, real-time high-rate GNSS observations can constrain magnitude estimates for events of $M_{\mathrm{w}}>7$ and for smaller earthquakes if a favorable station distribution exists in the epicentral region (Grapenthin et al., 2014b; Melgar, Geng, et al., 2015). OneHertz GNSS positions have been demonstrated to provide magnitude estimates that do not saturate, even for the largest events (e.g., Minson et al., 2014; Melgar, Crowell, et al., 2015; Crowell, Schmidt, et al., 2018). Furthermore, GNSS data can potentially provide accurate estimates of the final magnitude for large earthquakes before rupture completion (Melgar, Crowell, et al., 2015). 
For earthquakes that rupture large segments of the fault interface, which have the potential to cause the most damage and affect the most people, the locations of hypocenter and peak slip often do not coincide. However, point-source algorithms only provide the distance between a user's location and the epicenter, resulting in underestimated ground motions for such events. Knowing the approximate rupture extent enables use of a finite-fault distance metric such as the rupture distance or Joyner-Boore distance (Joyner and Boore, 1981), substantially improving the accuracy of predicted intensity (Colombelli $e t$ al., 2013; Ruhl et al., 2017). FinDer (Böse et al., 2015, 2018), which matches observed high-frequency peak ground acceleration (PGA) to line-source PGA templates, is the first seismic algorithm to be included in the ShakeAlert production system that aims to address fault finiteness. It estimates centroid location, length, strike, and origin time as the rupture progresses; magnitude is derived from scaling relationships. Further development is required to mitigate centroid location bias for dipping faults; inclusion of one-sided templates could better address offshore (i.e., megathrust) earthquakes (Böse et al., 2018).

GNSS observations also can constrain finite-fault algorithms, and real-time inversion of these data for fault orientation and spatially distributed slip characterizes the evolving rupture dimensions, moment release, and magnitude in detail. How rapidly this information can be obtained is a major consideration for EEW applications. Given the centimeter-level background noise typical of real-time GNSS position time series and the $1 / r^{2}$ decay of static displacements with distance $r$ from the source, during most earthquakes only relatively nearfield stations will resolve displacements and only after the rupture has grown sufficiently large, which requires several seconds (Allen and Ziv, 2011). Thus, outside of regions with sparse seismic networks (Grapenthin et al., 2017), we expect geodetic data are unlikely to contribute to the first alert issued by an EEW system that uses both seismic and geodetic data. Rather, geodetic data are likely to provide the greatest value to EEW by producing real-time estimates of rupture extent that enable more accurate updates of predicted shaking as the earthquake progresses, particularly for major and great earthquakes that rupture long distances as might occur on the Cascadia megathrust or the San Andreas fault. For example, Minson et al. (2018) showed that, depending on a user's chosen intensity threshold for receiving alerts, timely warning could be provided in the San Francisco metropolitan area for a scenario earthquake initiating near the Mendocino Triple Junction and rupturing toward the city. Using G-larmS (Grapenthin et al., 2014a) for a scenario $M_{\mathrm{w}} 8.7$ Cascadia earthquake, Ruhl et al. (2017) showed the potential for obtaining improved groundmotion predictions from a geodetically constrained finite-fault model before strong shaking reached more distant locations. In a retrospective analysis of $1-\mathrm{Hz}$ GPS data recorded during the 2011 Tohoku-Oki earthquake, ground motion predicted from a GPS-constrained finite-fault model (Minson et al., 2014) would have enabled timely alerts, and depending on choice of intensity threshold, would have outperformed a seismic point-source algorithm for some locations (Fig. 1). However, determining the best way to map geodetic source models into ground-motion predictions in real time is a field that the community has only begun to explore.

Because geodetic data are subject to different error sources than seismic data, they potentially provide an independent means to corroborate or refute alerts based on seismic observations alone. Where seismic monitoring is limited and for earthquakes that occur beyond the edges of monitoring networks (e.g., offshore), the additional information provided by real-time GNSS data can improve alert accuracy and timeliness compared with that achievable with seismic data alone (Grapenthin et al., 2017; Ruhl et al., 2017). Finite-fault model estimates of the dip and depth extent of slip would enable more accurate groundmotion predictions, especially for subduction zones, by more precisely defining rupture distance. Many GMPEs can incorporate the faulting mechanism, effects of hanging-wall/footwall deformation, and directivity. By providing such information, finite-fault rupture models can further improve the predictive ability of the GMPEs (e.g., Gregor et al., 2014). The potential contribution of geodetic observations in the event of complex ruptures that initiate on one segment and cascade to multiple fault strands through dynamic or static triggering should also be considered because the early portion of seismic waveforms may not initially reflect the full rupture extent. Examples include the $2016 M_{\mathrm{w}} 7.8$ Kaikōura (Hamling et al., 2017), $2012 M_{\mathrm{w}} 8.2$ Indian Ocean (Meng et al., 2012), and $2002 M_{\mathrm{w}} 7.9$ Denali (Hreinsdottir et al., 2006) earthquakes.

\section{GEODETIC POSITIONING AND ALGORITHMS UNDER DEVELOPMENT FOR SHAKEALERT}

Raw GNSS observables require complex real-time processing to obtain displacement measurements usable by EEW algorithms (e.g., Bock and Melgar, 2016). Central to this processing is the need to correct for GNSS satellite clock biases. One strategy is to compute positions relative to a reference station within the monitoring network such that satellite clock errors cancel out. However, for large-magnitude earthquakes causing significant displacements over a wide region, baseline positions may require further adjustment to address the coseismic motion of the reference station and capture network translation. Another strategy is to calculate absolute positions by obtaining and applying real-time clock corrections computed from data recorded by stations that are outside the region of interest or are globally distributed. Both processing strategies require additional ancillary information such as real-time satellite orbits. Variations in GNSS processing strategies at different analysis centers can result in slightly different position time series. However, these variations, typically a few centimeters, are small compared with the near-field displacements from many $M_{\mathrm{w}} 7+$ earthquakes. The ability of positioning software to recover quickly from loss of lock on satellite signals could have a greater impact on data quality for EEW.

Figure 2 shows the distribution of permanent GNSS stations operated by ShakeAlert partners in the alert region. Although each GNSS network operator conducts real-time 
(a)

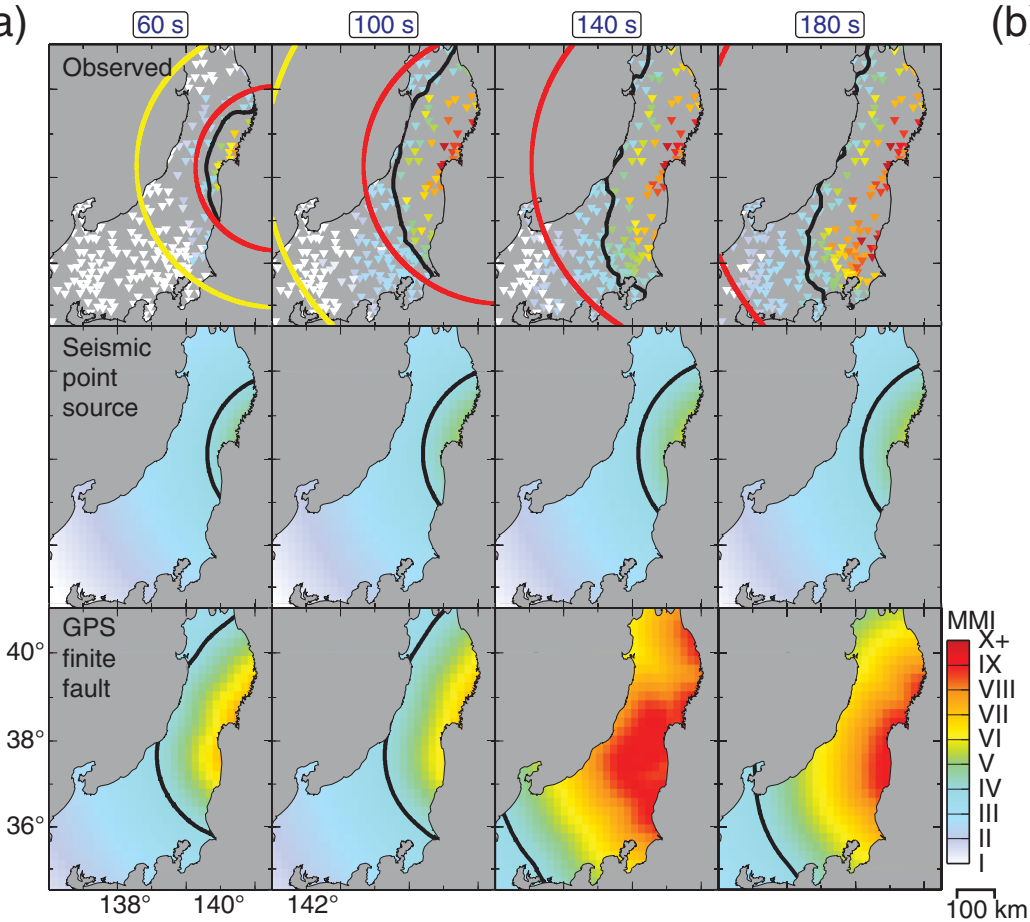

(b)

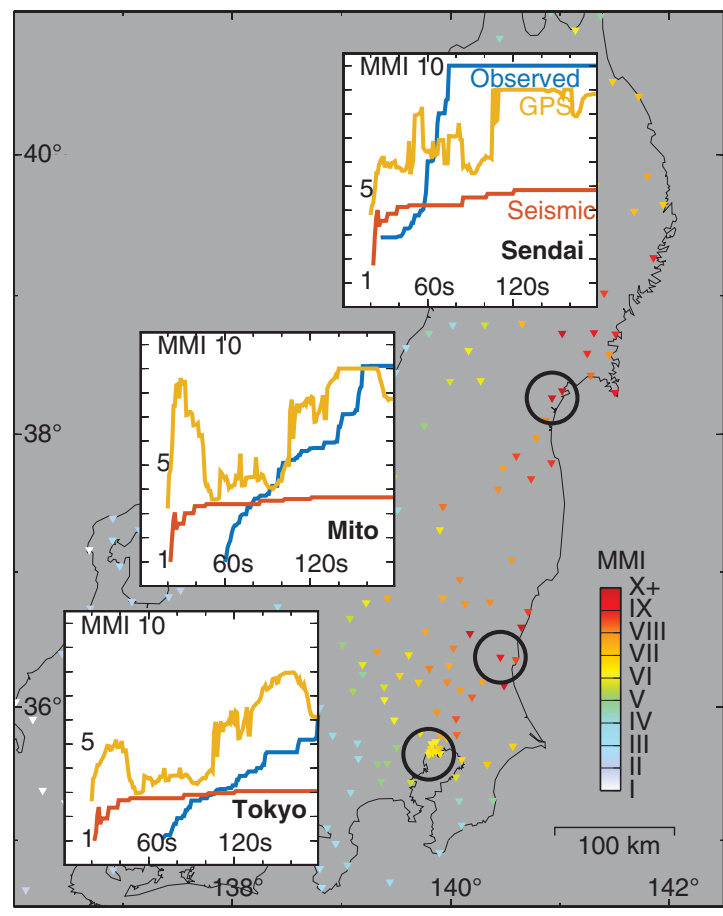

A Figure 1. Observed shaking intensity as a function of time for the $2011 M_{\mathrm{w}} 9.0$ Tohoku-0ki earthquake and that predicted from seismic point-source and Global Positioning System (GPS)-constrained finite-fault models. (a) Top row: maximum modified Mercalli intensity (MMI) at KiK-net strong-motion stations observed as of the elapsed times (relative to earthquake origin time) indicated at the top of each column $(60,100,140$, and $180 \mathrm{~s})$. Yellow and red circles indicate distance to which the $P$ wave and $S$ wave, respectively, had traveled at each elapsed time. Black contour delineates observed intensity of MMI IV at each elapsed time. Middle row: MMI predicted from a seismic point-source model calculated using the Japanese Meteorological Agency's earthquake early warning magnitude and location estimates at the corresponding elapsed times (Hoshiba and Ozaki, 2014); ground-motion prediction equations from Si and Midorikawa (2000). Black contour delineates predicted intensity of MMI IV at each elapsed time. Bottom row: MMI predicted from GPSconstrained finite-fault model (Minson et al., 2014) at each elapsed time. Black contour delineates predicted intensity of MMI IV. (b) Time series of observed MMI (blue) and MMI predicted from the seismic point-source (red) and GPS finite-fault model (yellow) for three cities circled in black. Triangles show maximum observed MMI at each strong-motion station.

processing of data from its own network, most also process real-time data from other networks to compute clock corrections, expand the list of possible reference stations, or increase coverage for specific monitoring and scientific applications (Fig. 3). Each institution that operates a GNSS network generally processes real-time data from all stations in a centralized manner on servers residing at its facility. However, GNSS receiver manufacturers are beginning to offer absolute positioning onboard the instrument using global clock corrections obtained at the field site from a geosynchronous satellite, potentially removing the need for centralized real-time processing in the future. Some stations in the ShakeAlert region are actively streaming positions calculated on-receiver (Fig. 4). () Figure $S 1$ (available in the electronic supplement to this article) depicts ShakeAlert GNSS data processing.

Although the ShakeAlert GNSS network operators have each evaluated aspects of their own real-time positioning results, a comprehensive assessment of all operators' real-time position streams that quantifies typical signal-to-noise ratio, the ability of the position solution to recover from loss of lock on the satellite signal, and other attributes is still needed.
The results of such analyses will provide data quality measures that geodetic algorithms can use to select or weight observations. These results will also highlight the strengths and weaknesses of different processing approaches and clarify whether any strategy performs substantially better or worse than the others. Routine archiving of raw real-time data and processed real-time position solutions would provide input for such an evaluation but has not yet been instituted uniformly.

We have developed three algorithms, named BEFORES, G-FAST, and G-larmS, that use real-time geodetic displacement measurements for magnitude estimation and to characterize fault orientation, rupture length, and slip distribution. In general, the geodetic algorithms are triggered by the first alert issued by the EEW system. This is currently based on seismic data and provides a preliminary epicenter, magnitude, and origin time. The geodetic algorithms use various approaches to incorporate these pieces of information and other prior knowledge regarding fault geometry to generate updated source characterizations. For large earthquakes, GNSS-derived displacements and updated magnitude estimates are possible while the rupture is in progress (Melgar, Crowell, et al., 2015; 

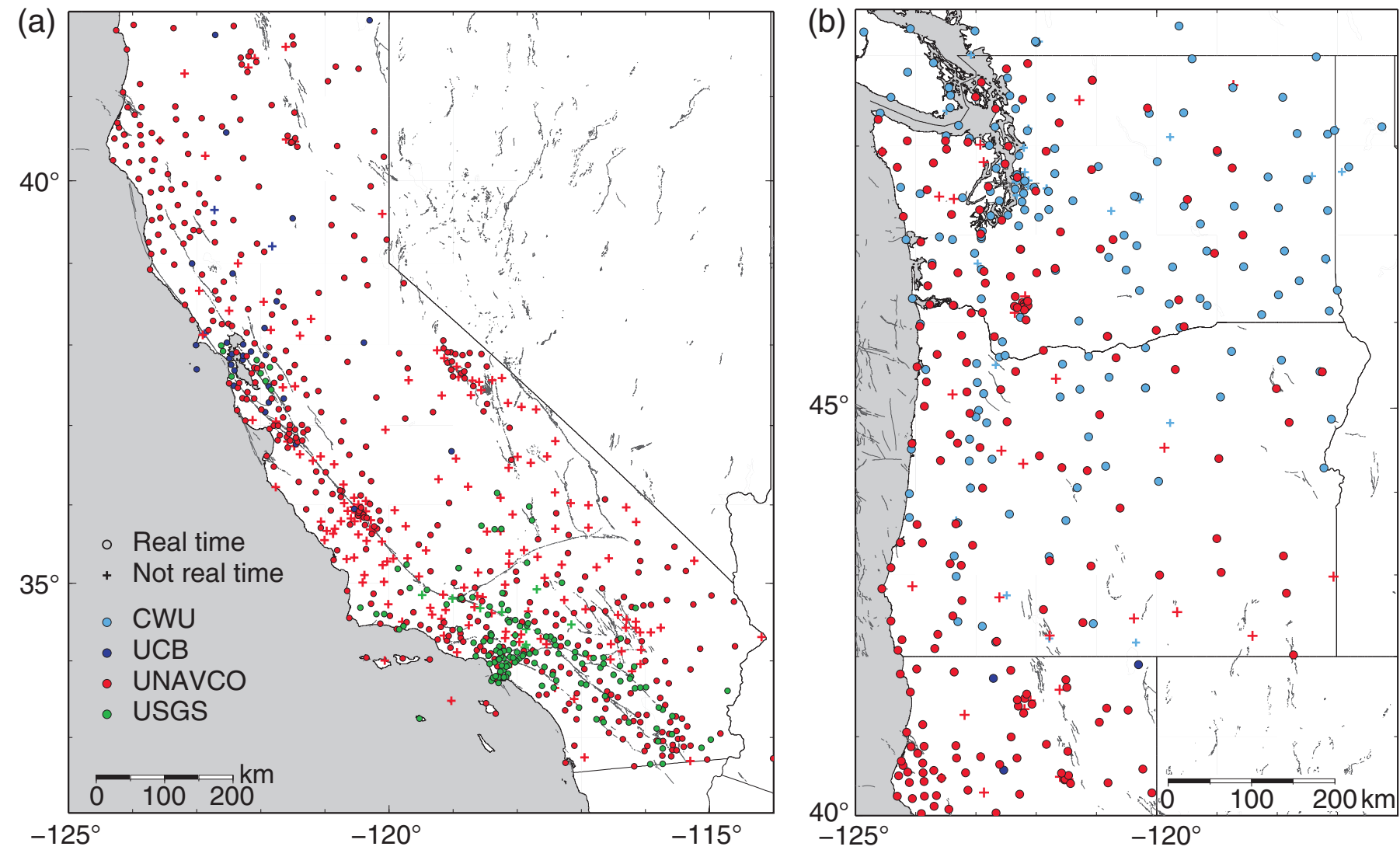

- Figure 2. Real-time and non-real-time permanent Global Navigation Satellite System (GNSS) sites in the ShakeAlert region (Washington, Oregon, and California) operated by partner institutions Central Washington University (CWU), University of California at Berkeley (UCB), UNAVCO Inc., and U.S. Geological Survey (USGS). Some network operators partner with additional state, local, and private agencies. See Data and Resources for links to detailed information regarding geodetic networks. (a) California and (b) Cascadia; some sites located in Canada are shown for reference. Circles, sites operating in real time as of April 2018; crosses, sites not transmitting real-time data; gray lines, faults with historic and Holocene ruptures.

Melgar and Hayes, 2017). The evolution of the magnitude estimates from GNSS algorithms, as with seismic algorithms, is controlled by the evolution of the seismic source (e.g., Minson et al., 2014, 2018; Melgar, Crowell, et al., 2015). Currently, no ShakeAlert algorithm jointly analyzes seismic and geodetic data streams; rather, the evolving source parameter estimates from the seismic EEW algorithms are continually reconciled by a separate module to provide input for ground-motion prediction. This module will be extended to include geodetic algorithms in the future. Although geodetic algorithms are not yet implemented for real-time testing in the ShakeAlert system, Grapenthin et al. (2014b) present results from real-time analysis of the $2014 M_{\mathrm{w}} 6$ South Napa earthquake by G-larmS. Table 1 summarizes key features of the geodetic algorithms developed thus far as part of the ShakeAlert project.

\section{A FRAMEWORK FOR TESTING GEODETIC EEW ALGORITHMS}

\section{Evaluation Criteria}

For a new algorithm to be incorporated into ShakeAlert, it should substantially improve overall system performance.
Meier (2017) showed that in a best case scenario the inclusion of finite-fault information, such as that available from geodetic algorithms, significantly improved ground-motion alert accuracy and timeliness. However, his tests assumed that the correct magnitude and fault dimensions were known at the moment of the $P$-wave trigger. In reality, the degree of improvement a given algorithm offers varies depending on factors such as earthquake magnitude, mechanism, seismotectonic setting, and the time needed to determine this information. Thus, an algorithm may add value to the EEW system as a whole even though the algorithm does not improve performance for every earthquake the system encounters.

ShakeAlert products include an earthquake source description (e.g., origin time, magnitude, location, and rupture length) and predicted ground motion. To date, seismic and geodetic EEW algorithms under development for ShakeAlert estimate source parameters, which subsequently serve as input to GMPEs for estimating ground motion (Given et al., 2014 and planned revision). As a result, algorithm evaluation has focused largely on the ability of a method to accurately recover source parameters. However, predicted shaking intensity is one criterion for issuing and updating alerts. Furthermore, it is 

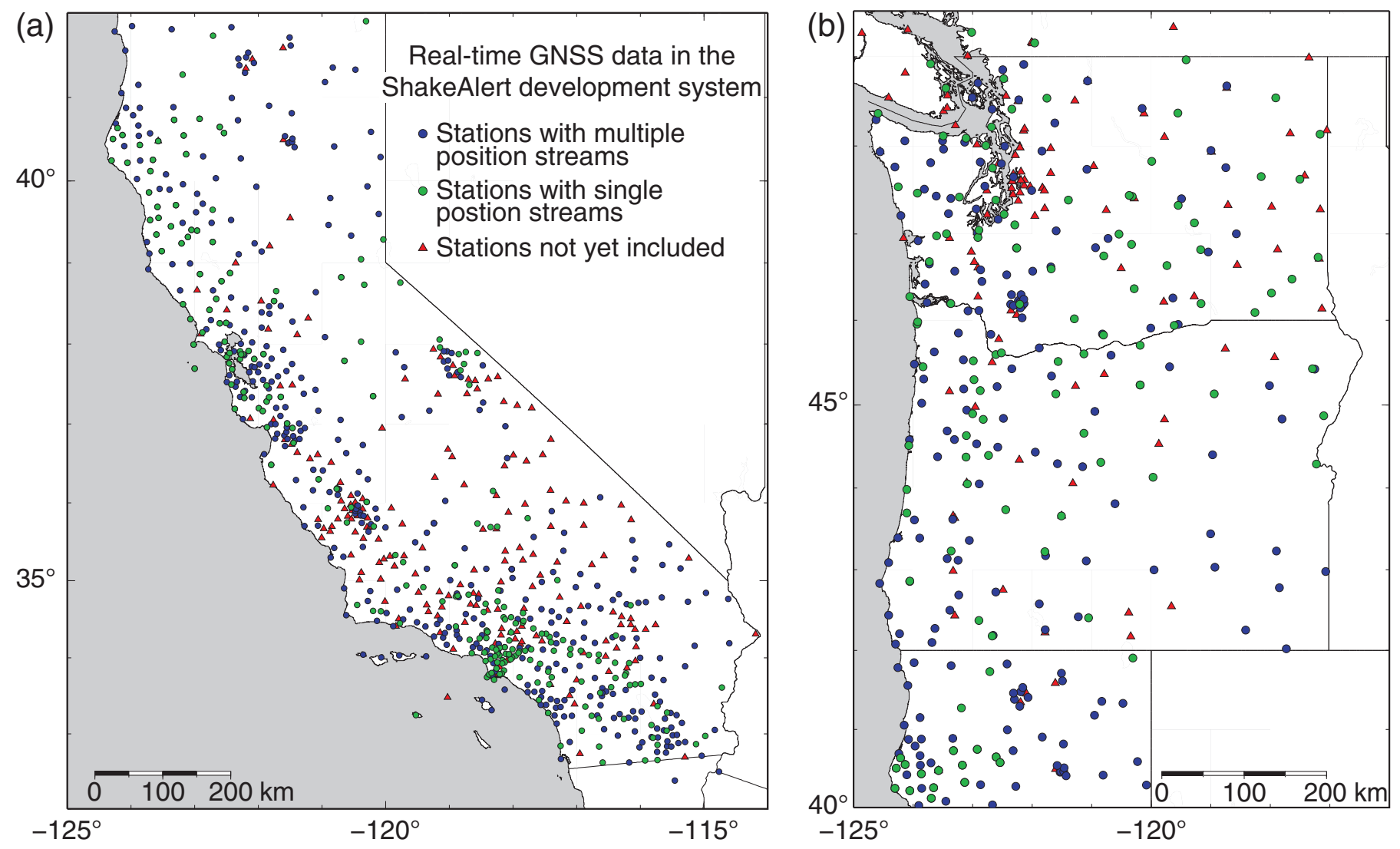

A Figure 3. Stations in the ShakeAlert region for which real-time GNSS position streams are transmitted to ShakeAlert development systems as of April 2018. (a) California and (b) Cascadia. Blue circles, real-time positions calculated at multiple data centers or using multiple methods at the same data center; green circles, real-time positions calculated at one data center using one processing method; red triangles, stations for which real-time positions are not yet available in the ShakeAlert system (although they may have real-time telemetry).

anticipated that in the future, ShakeAlert will combine groundmotion predictions and associated uncertainties from multiple EEW algorithms, potentially including ones that estimate ground motion directly (e.g., Kodera et al., 2018), in a probabilistic framework (Minson et al., 2017). The relevant question then is how accurately an EEW system can predict the ground shaking before it arrives at a user's location. Metrics for evaluating algorithms must address the accuracy and timeliness of the ground-motion predictions they provide. Recognizing this, in addition to evaluating point-source algorithms with respect to estimated magnitude, epicenter, origin time, and amount of warning, the ShakeAlert Testing and Certification (T\&C) platform (Cochran et al., 2017) assesses algorithms on the basis of predicted ground motion, building on the work of Meier (2017).

Cochran et al. (2017) present candidate metrics to be used by the $\mathrm{T} \& \mathrm{C}$ platform for ground-motion-based algorithm assessment. Alert outcomes are classified as true positive, false positive, true negative, or false negative based on the accuracy and timeliness of predicted modified Mercalli intensity (MMI) at user locations relative to a predefined MMI threshold. Summary metrics derived from these alert classifications, coupled with performance standards, form the basis for evaluating algorithm and system performance (see (E) electronic supple- ment to this article). Aggregating results for one algorithm over many test earthquakes helps characterize its overall performance. Comparing the algorithm's results for multiple earthquakes allows exploration of its capabilities as a function of event type, potentially illuminating categories of earthquake sources for which the algorithm is better suited. These metrics can also be used to assess the impact of including or excluding specific algorithm features on overall EEW system performance. The summary metrics to be used by $\mathrm{T} \& \mathrm{C}$ are evolving, for example, to incorporate a user's cost-benefit ratio.

\section{Objectives for Initial Geodetic Algorithm Testing}

Geodetic algorithm developers have independently used various test datasets and metrics to demonstrate the capabilities of their approaches. The next step is to evaluate the full set of ShakeAlert candidate geodetic algorithms on the basis of timely and accurate ground-motion prediction in a self-consistent manner. Here, we outline a framework for an initial stage of geodetic algorithm evaluation modeled after the approach embodied by the T\&C platform. The objective of this initial geodetic testing stage, however, is distinct from that of formal T\&C. The purpose of the latter is to assess whether an algorithm is suitable for deployment in the ShakeAlert production system and considers the method's alerting performance, 

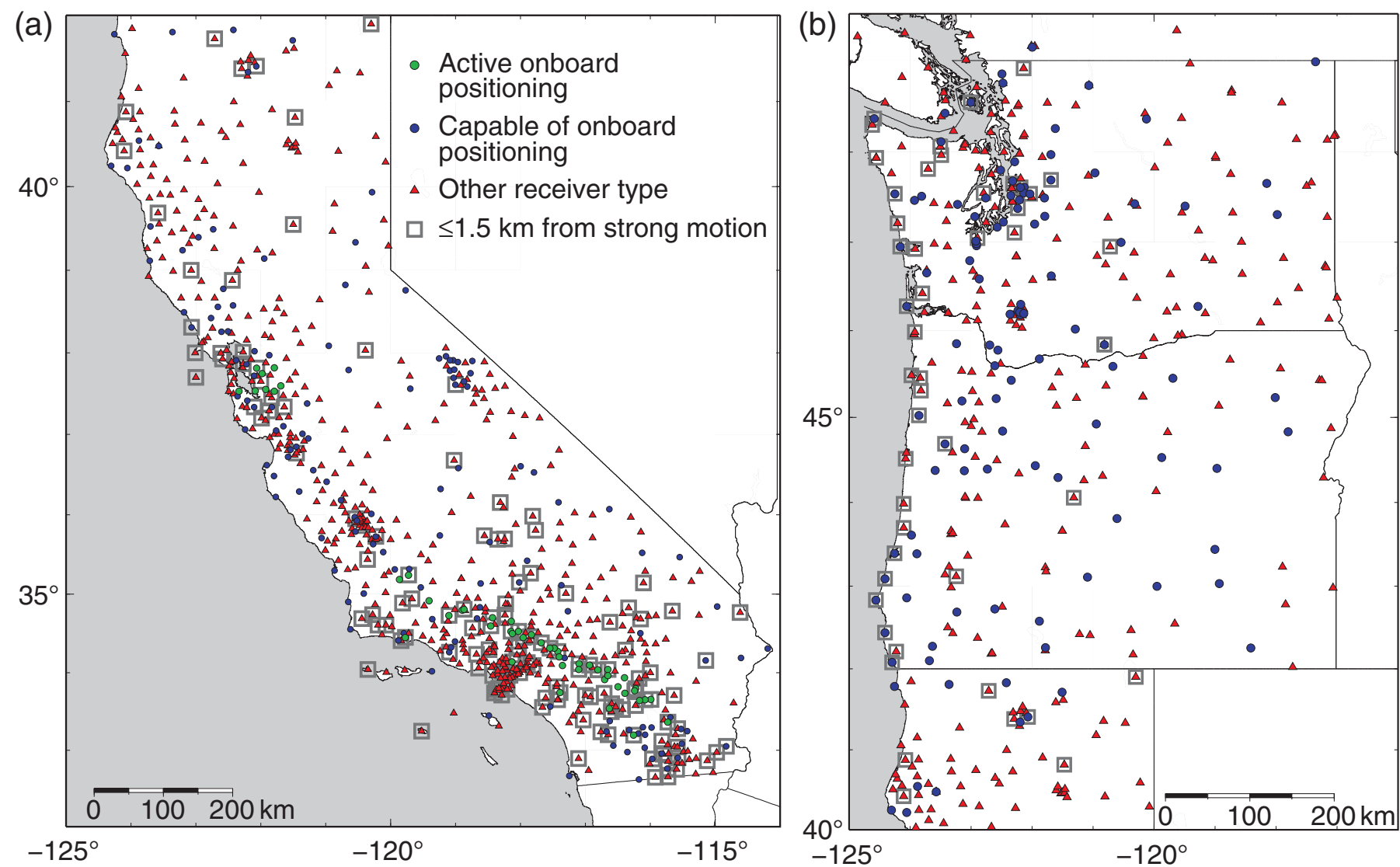

A Figure 4. Onboard positioning capability of stations in the ShakeAlert region as of April 2018. (a) California and (b) Cascadia. Green circles, stations for which onboard positioning is activated and position streams are available to ShakeAlert; blue circles, stations with receivers capable of onboard positioning but for which the capability is not currently used; red triangles, stations without receivers capable of onboard positioning; gray squares, stations that are located within $1.5 \mathrm{~km}$ of an Advanced National Seismic System continuous strong-motion station (information as of November 2017).

robustness when presented with spurious signals, and the efficiency and stability of the software implementation in a realtime setting (Cochran et al., 2017). In contrast, the objective of the initial geodetic algorithm testing is twofold: (1) to quantify the improvement to overall system performance offered by incorporating geodetic input and (2) to illuminate current geodetic algorithm capabilities, opportunities for combining features into a single, more powerful, approach, and avenues for further development.

The initial testing will adopt ground-motion metrics consistent with those in use by $\mathrm{T} \& \mathrm{C}$ as the primary criteria for evaluating each algorithm's success in providing correct and timely alerts for user-specified ground-motion thresholds (see (E) electronic supplement to this article). Although not used directly to evaluate performance, considering additional criteria such as the amount of warning time provided, quality of ground-motion predictions compared with ground truth, and accuracy of earthquake source parameters estimated during the test runs might aid continued algorithm refinement by further illuminating methodological strengths and weaknesses. A full assessment of the timeliness with which geodetic algorithms can provide alerts must also account for system latency, including the time needed to acquire real-time GNSS data, calculate positions, and run the algorithms. Follow-on testing that exercises the ShakeAlert seismic system and geodetic algorithms jointly, that estimates ground motion after reconciling source parameter estimates from all algorithms and that ingests observed position streams in real time will quantify the value added by geodetic algorithms over a seismic-only system in a comprehensive and self-consistent manner. The results of initial testing will guide further geodetic algorithm development before submission to $\mathrm{T} \& \mathrm{C}$.

\section{Available Test Data}

Online testing using real-time data will be required for algorithms to be accepted into a production system. However, the frequency of earthquakes in the magnitude range to which real-time GNSS data are sensitive is insufficient in the western United States for thorough evaluation of individual algorithm performance or the contribution of geodetic algorithms to the overall EEW system using real-time data alone. Many aspects of the geodetic algorithms can be tested using observations from globally distributed historic events replayed in simulated realtime mode. High-rate (typically $1 \mathrm{~Hz}$ ) GPS position time series 
Table 1

Summary of the Three Global Navigation Satellite System (GNSS) Based Earthquake Early Warning (EEW) Algorithms under Development through the ShakeAlert Collaboration

\begin{tabular}{|c|c|c|}
\hline & BEFORES & G-FAST \\
\hline Reference & Minson et al. (2014) & Crowell et al. (2016) \\
\hline Trigger & Alert from seismic EEW & Alert from seismic EEW \\
\hline $\begin{array}{l}\text { GNSS processing } \\
\text { type }\end{array}$ & $\begin{array}{l}\text { Precise point positions, } \\
\text { network baselines, } \\
\text { mix of both }\end{array}$ & Precise point positions \\
\hline $\begin{array}{l}\text { Stations } \\
\text { used }\end{array}$ & Sites within $P$-wave range & Sites within $S$-wave range \\
\hline Station weighting & $\begin{array}{l}\text { Weighted by displacement } \\
\text { amplitude }\end{array}$ & $\begin{array}{l}\text { Weighted by proximity to } \\
\text { epicenter from seismic trigger }\end{array}$ \\
\hline Observable & $\begin{array}{l}\text { Accumulated static offset } \\
\text { at each timestep }\end{array}$ & $\begin{array}{l}\text { Peak ground displacements } \\
\text { (PGD), accumulated static } \\
\text { offset at each timestep }\end{array}$ \\
\hline
\end{tabular}

Epicenter from seismic EEW

Epicenter from seismic EEW

Initial fault location Centered on epicenter from seismic EEW; top edge intersects Earth's surface

Initial fault

dimensions
Largest possible rupture length and width anticipated for the seismotectonic region
Centered on epicenter from seismic EEW; depth from grid search over Global Positioning System (GPS) moment tensor solutions

Rupture length and width from Dreger and Kaverina (2000) using magnitude from GPS-derived moment tensor
Method for obtaining fault strike and dip

\section{Parameters} estimated

Magnitude estimate

Model updates

Data updates
Grid search over all strikes and dips in parallel

2D slip distribution; preferred strike and dip (from grid search)

From slip distribution

Every second

Every second and as $P$ waves reach more sites using epicenter and origin time from seismic alert updates
Uses strike and dip from GPS moment tensor

2D slip distribution; strike and dip from GPS-constrained centroid moment tensor (Melgar et al., 2012)
(a) From PGD-scaling and
(b) from slip distribution

Every second

Every second and as $S$ waves reach more sites using epicenter and origin time from seismic alert updates
G-larmS

Grapenthin et al. (2014a)

Alert from seismic EEW

Precise point positions, network baselines, mix of both

Sites within $S$-wave range inside a magnitude-dependent radius around the initial epicenter

Equal weighting

Accumulated static offset at each timestep

Epicenter from seismic EEW, fault models based on regional tectonics and/or fault catalog of precomputed Green's functions

Centered on hypocenter from seismic EEW (regional model) and/or selected based on epicenter (fault catalog)

Regional model: rupture length and width from Wells and Coppersmith (1994) using magnitude from seismic EEW and plausibility constraints for seismotectonic setting; fault catalog: length and width obtained from catalog for complex fault geometries

Checks several strikes and dips anticipated for the region in parallel and/or based on fault catalog

2D slip distribution; preferred strike and dip (from among those tested)

From slip distribution

Every second

Every second and as $S$ waves reach more sites using epicenter and origin time of initial trigger

(Continued next page.) 
Table 1 (continued)

Summary of the Three Global Navigation Satellite System (GNSS) Based Earthquake Early Warning (EEW) Algorithms under Development through the ShakeAlert Collaboration

\begin{tabular}{|c|c|c|c|}
\hline & BEFORES & G-FAST & G-larmS \\
\hline Test earthquakes & $\begin{array}{l}2011 M_{\mathrm{w}} 9.0 \text { Tohoku-Oki and } \\
2003 M_{\mathrm{w}} 8.3 \text { Tokachi-Oki } \\
\text { earthquakes (Minson et al., } \\
\text { 2014) }\end{array}$ & $\begin{array}{l}2010 M_{\mathrm{w}} 8.8 \text { Maule, } 2014 M_{\mathrm{w}} 8.2 \\
\text { lquique, } 2015 M_{\mathrm{w}} 8.3 \text { Illapel } \\
\text { (Crowell, Schmidt, et al., 2018), } \\
\text { and } 2016 M_{\mathrm{w}} 7.8 \text { Kaikoura } \\
\text { earthquakes (Crowell, Melgar, } \\
\text { et al., 2018) }\end{array}$ & $\begin{array}{l}2010 M_{\mathrm{w}} 7.2 \text { El Mayor-Cucapah } \\
\text { earthquake (Grapenthin et al., } \\
2014 \mathrm{a} \text { ), } 2014 M_{\mathrm{w}} 6.0 \text { Napa } \\
\text { earthquake, and California } \\
\text { (Grapenthin et al., 2014b), } \\
29 \text { global earthquakes of } \\
M_{\mathrm{w}} 6-9 \text { (Ruhl et al., 2018) }\end{array}$ \\
\hline $\begin{array}{l}\text { Synthetic } \\
\text { tests }\end{array}$ & $\begin{array}{l}\text { Hayward fault scenario } \\
\text { (Minson et al., 2014) }\end{array}$ & $\begin{array}{l}2001 M_{\mathrm{w}} 6.8 \text { Nisqually, Cascadia } \\
\text { (Crowell et al., 2016), Cascadia } \\
\text { Scenario Suite (1300 events, } \\
\text { Melgar et al., 2016) }\end{array}$ & $\begin{array}{l}\text { Hayward fault scenario } \\
\text { (Grapenthin et al., 2014a), } \\
\text { Cascadia scenario suite } \\
\text { (1300 events, Melgar et al., } \\
\text { 2016), coupled seismic- } \\
\text { geodetic } M_{\mathrm{w}} 8.7 \text { Cascadia } \\
\text { event (Ruhl et al., 2017) }\end{array}$ \\
\hline
\end{tabular}

recorded during $M_{\mathrm{w}} 6.0-9.0$ earthquakes occurring between 2003 and 2016 coupled with seismic data for the same events (Melgar, Crowell, et al., 2015; (E) Table S1) will be a key component of the geodetic test suite. However, we must supplement these observations with synthetic data to adequately cover a broad range of event characteristics. The test suite will thus incorporate synthetic data generated from simulated ruptures of the Cascadia megathrust $\left(1300 M_{\mathrm{w}} 7.8-9.3\right.$ scenarios for 64 stations; Melgar et al., 2016), the $M_{\mathrm{w}} 6.8$ Nisqually earthquake (26 stations; Crowell et al., 2016), Hayward fault scenarios $\left(39 M_{\mathrm{w}} 6.6-7.2\right.$ scenarios computed up to $0.5 \mathrm{~Hz}$ and 6 computed to $10 \mathrm{~Hz}$ at $>1000$ sites; Aagaard, Graves, Rodgers, et al., 2010; Aagaard, Graves, Schwartz, et al., 2010; four $M_{\mathrm{w}} 7$ scenarios with 2400 stations, Rodgers et al., 2018), and others as they become available. Use of test events (real and synthetic) that span the range of magnitudes, mechanisms, and geographic locations of interest for the EEW system can help identify situations in which the algorithms are likely to be most impactful and delineate the expected range of algorithm performance. The test suite will be maintained in a centralized repository accessible by the scientific community for further research and development.

Synthetic datasets are unlikely to fully reflect factors such as late and missing data or sites with high ambient noise levels. To some extent, these aspects of the EEW system can be simulated based on knowledge of real-time geodetic network performance (e.g., Crowell et al., 2016). Realistic noise can be included by modulating synthetic earthquake waveforms onto time series of real background noise recorded during periods of no seismic activity (e.g., Grapenthin et al., 2014a; Minson et al., 2014 based on noise characterization of Langbein and Bock, 2004). Synthetic data that faithfully capture both the high-frequency waveform contributions and the static offsets are under development for use in joint testing of seismic and geodetic algorithms (Aagaard, Graves, Schwartz, et al., 2010; Ruhl et al.,
2017). Determining the best methods for validating broadband synthetics is an area of active research within the ShakeAlert project. The results of this validation will guide the relative weighting of the numerous synthetic earthquakes versus the few real events in evaluating algorithm performance.

\section{Test Implementation}

The initial stage of geodetic algorithm testing will evaluate individual performance against ShakeAlert relevant metrics and will enable apples-to-apples comparison among algorithms. To this end, initial testing is being conducted on the ShakeAlert development system using the simulated and historic data described earlier. The development system provides a space for testing new algorithms and substantial changes to existing ones in an environment that mirrors the production system, for example, using the Earthworm software (see Data and Resources) to store and retrieve data on ring buffers and by use of the ActiveMQ messaging system adopted by ShakeAlert for transmitting data and alert messages among system components (Given et al., 2014 and planned revision). The geodetic algorithm code will be implemented on the development machines at the alerting centers (University of Washington, University of California at Berkeley, U.S. Geological Survey [USGS] Menlo Park, and the California Institute of Technology). Data for each test event will be replayed in simulated real-time mode using the Earthworm "tankplayer" module to supply input to the algorithms.

The geodetic algorithms generally initiate calculations upon receiving a trigger message from the EEW system based on $P$-wave arrivals from seismic data. Most of the currently available synthetic displacement waveforms do not include the high-frequency components needed for seismic-based EEW. Thus, initial testing with synthetic datasets will use a simulated trigger message based on the source magnitude, location, and origin time used in the synthetic waveform generation. Simu- 
lated triggers can also be used for real events for which seismic data are not readily available. The simulated trigger information can be perturbed to reflect realistic errors observed in seismic algorithms' first alerts using, for example, the archived performance history of those algorithms running in the production system.

Each geodetic algorithm will produce an event source message that includes the estimated magnitude, slip, and information describing the source geometry such as length, orientation, and centroid location. The trigger and event source message formats will be consistent with those adopted by the ShakeAlert system. For algorithms such as the three described in this article that do not output ground motion directly, we will calculate ground motion identically from the source parameters contained in each algorithm's event source message using the ShakeAlert EQinfo2GM module (Given et al., 2014 and planned revision), which includes the GMPEs and groundmotion-to-intensity conversions used by all ShakeAlert algorithms. These are chosen to be consistent with those used to generate regional ShakeMaps. The algorithms will generate updated messages as they incorporate additional data, and the predicted ground-motion product will evolve over time based on the updated source information, providing input for calculating the metrics used to assess algorithm performance.

\section{THE PATH TO A STREAMLINED, ROBUST GEODETIC ALGORITHM}

The long-term operability of a robust EEW system requires continuity of expertise to carry out maintenance, troubleshooting, and future enhancements. In the context of software development, this goal led to an ongoing streamlining effort and formalized ShakeAlert design standards. These standards define requirements for source code language, software testing, documentation, metadata, configuration files, and messaging protocols; institute use of a designated code repository and version control; and promote use of a modular code base. A streamlined production system will incorporate those algorithms that provide uniquely valuable information as demonstrated through formal $\mathrm{T} \& \mathrm{C}$ without adding undue complexity to the system. Aspects of both the real-time GNSS data handling and the geodetic algorithms may be amenable to streamlining.

Unless the quantitative comparison of real-time processing results discussed earlier reveals substantial deficiencies in a network operator's real-time processing system, the potential benefits of standardizing the real-time processing approach overall or the choice of processing software in particular probably does not outweigh the costs operators would incur to build completely new processing infrastructure.

However, in the data transmission framework described earlier, it is evident that ShakeAlert centers are likely to receive multiple GNSS position streams for the same station because network operators process overlapping sets of stations. The positions, although typically consistent within a few centimeters, will rarely be identical because of use of different physical models and estimation strategies. Although this could mitigate adverse effects arising from errors in any one data provider's solutions, reconciling duplicate input streams with varying latencies and data gaps adds a level of complexity to the system and presents a target for streamlining.

One approach to reconciling positions merges multiple position streams using a Kalman filter, producing a potentially more accurate consensus stream for each station. Under testing for tsunami warning applications (Stough and Green, 2016), the merging software waits a predefined maximum time to receive a given epoch's data from multiple network operators, likely introducing unacceptable latency for EEW. A modified version could pass through the first arriving solution for stations for which only one data source had reported at that epoch, allowing shorter wait times. EEW algorithms could proceed with currently available observations, although possibly at the expense of improved accuracy. At subsequent epochs, the filter would incorporate late data to update the merged streams, and algorithms could use the merged data in ensuing calculations.

The fundamental input used by geodetic algorithms for earthquake source characterization is the $3 \mathrm{D}$ displacement of each GNSS station relative to its pre-event location as a function of time. Derivation of displacements from the input position streams is an integral part of each geodetic EEW algorithm currently under consideration for ShakeAlert. The way that each algorithm estimates displacements differs in details such as the length of time data are buffered, the time windows used for position averaging, and which subset of available stations is used as rupture progresses. These analysis choices are related to the way in which the system handles redundant data streams but are also algorithm specific. Further consideration should be given to the possibility of all algorithms' using the same code for displacement estimation.

As discussed earlier, the first stage of geodetic algorithm testing will highlight the most valuable algorithm features to carry forward. These will form the basis for a streamlined geodetic algorithm, and will, in turn, more concretely define the input requirements. Running the algorithms continuously on real-time data from ShakeAlert GNSS networks will highlight the impact of modifications to networks and data processing schemes as well as enable more comprehensive assessment of system latency and algorithm response in low signal-to-noise ratio situations. Careful review of initial results obtained using the test suite in terms of alert accuracy, timeliness, and source parameter metrics will also illuminate the impact of strategies used by different algorithms for combining data and estimating displacements. Completing the first stage of testing will provide the context needed to enable effective exploration of opportunities for streamlining geodetic algorithm components, including those related to data preparation.

Subsequently, a geodetic algorithm composed of modules that incorporate the best components of currently available approaches can be submitted for formalized, double-blind T\&C with the goal of implementation in the ShakeAlert production system. Developers, including those not yet involved in ShakeAlert, will undoubtedly continue to improve their methodology, 
and the capabilities and density of real-time geodetic networks will continue to grow. Consideration of additional data types (e.g., borehole strain) and new algorithms or substantive improvements to existing ones will be ongoing and will follow the process outlined here.

\section{GNSS NETWORK UPGRADES IN SUPPORT OF SHAKEALERT}

The GNSS component of ShakeAlert requires real-time station spacing that is sufficient to characterize the moment, mechanism, and rupture extent of earthquakes that would impact population centers within the ShakeAlert region. Although preliminary assessment for particular scenario earthquakes (Ruhl et al., 2017) suggests that adequate station coverage exists throughout much of the region, further evaluation is needed to assess the required station distribution based on earthquake source type and individual geodetic algorithm, as well as the interplay between station distribution and alert timeliness. The determination of station locations that offer the greatest benefit for issuing and updating alerts should consider both the relative likelihood of earthquake ruptures in the ShakeAlert region and the time frame within which observable displacements from these ruptures would reach the candidate GNSS stations relative to the time at which strong shaking would reach users. It must also consider whether, in aggregate, a given station provides unique or redundant information to illuminate model parameters for the events of interest.

The effective GNSS station spacing actually depends on both the distribution of stations relative to potential hypocenters and data completeness because data gaps can significantly impair real-time position quality (Crowell et al., 2016). Therefore, ShakeAlert GNSS network upgrades should involve strengthening the data pathways from existing stations, including elimination of single points of failure, combined with installation of new stations as needed to ensure to the greatest extent possible the alerting centers' robust access to the realtime positions. Doing so would substantially increase the likely contribution of geodetic algorithms to ShakeAlert, and this strategy is to be included in the planned 2018 revision to the ShakeAlert Technical Implementation Plan (D. D. Given, written comm., 2018).

In practice, the latency introduced by data processing, data transmission, and analysis by ShakeAlert algorithms is an additional factor that controls the overall system performance whether in the context of seismic or geodetic data. However, unlike fundamental source and wave propagation processes, it may be possible to reduce the operational contribution to alert latency with code and hardware refinements. GNSS receivers capable of absolute positioning have been installed at some ShakeAlert partner sites (Fig. 4). On-receiver positioning could eliminate potential points of failure that exist in centralized processing at network operator institutions and may reduce latency by instead sending real-time positions directly to alerting centers at the latency of the broadcast clock products. The latter would require alerting centers to translate position streams from receiver-specific formats to the geoJSON format (see Data and Resources) adopted by ShakeAlert for real-time GNSS positions. Implementation of a translation module on-receiver (in collaboration with receiver manufacturers) or at the field site upstream of data transmission to alerting centers are alternative models for consideration. Generation of instantaneous receiver velocities from time-differenced phase observations (Grapenthin et al., 2018) does not require clock corrections and could be implemented on-receiver or at a processing center. These velocities can be used directly or integrated to displacements with precision on par with real-time positioning methods (Colosimo et al., 2011; Benedetti et al., 2014).

Where real-time GNSS receivers and accelerometers are collocated (defined as $\leq 1.5 \mathrm{~km}$ apart), these data can be synthesized to produce a seismogeodetic displacement time series that records the $P$-wave arrival, dynamic motions, and static offsets (Bock et al., 2011) with substantially lower noise than displacements calculated from GNSS data alone. Using data from accelerometers collocated with drilled-braced GNSS monuments, Goldberg and Bock (2017) resolved displacements sufficiently small to detect $M_{\mathrm{w}} \sim 5$ events. Crowell et al. (2013) found that a magnitude scaling relationship that used the peak displacement amplitude (Pd) measured during the first $5 \mathrm{~s}$ of seismogeodetic time series showed less magnitude saturation with similar latency compared with the one based on displacement from doubly integrated, high-pass-filtered accelerometer data alone. This approach to magnitude estimation could be incorporated in a future ShakeAlert geodetic algorithm if further testing on data from real events corroborates the results of Crowell et al. (2013). The relatively small number of collocated real-time GNSS and accelerometers worldwide that have recorded large earthquakes limits the number of test datasets available. Collocating strong-motion and real-time GNSS instruments might both provide data for development of new geodetic algorithms and enable more efficient network upgrades through shared power, telemetry, and land-use permits. Expanding the number of collocated instruments in the ShakeAlert region (Fig. 4) is aligned with formal inclusion of real-time GNSS networks in ANSS (USGS, 2017).

The contribution that spatially dense arrays of low-cost instruments (seismic and geodetic) might make to operational early warning systems is a topic of active research and development (e.g., Cochran et al., 2009; Clayton et al., 2011; Minson et al., 2015; Kong et al., 2016). In this scenario, the large number of instruments counterbalances the higher noise levels inherent in the data they produce, effectively increasing the overall signal-to-noise ratio. Low-cost sensors can provide input to the same algorithms as do observatory-grade networks and in the future may help augment EEW capabilities or expand alerting to sparsely instrumented regions.

\section{CONCLUSIONS}

Real-time GNSS data directly measure arbitrarily large displacements, including static offsets, thus providing unique observations that complement seismic data for EEW. Incorporating 
geodetic measurements into EEW systems is an avenue for mitigating magnitude saturation, tracking earthquake rupture as it unfolds, and constraining finite-fault models that improve source-user distance measures for GMPEs, all of which lead to more accurate ground-motion alerts. Moreover, retrospective application of the BEFORES, G-FAST, and G-larmS geodetic EEW algorithms to data from recent major earthquakes and scenario events suggests that this information can be obtained quickly enough to provide timely improvements to predicted shaking, although the amount of warning received by a given user depends on additional factors such as the shaking intensity threshold for which they choose to receive alerts. Based on results to date, we anticipate that a geodetic component of ShakeAlert will substantially improve alerting capability, particularly for major and great earthquakes that rupture large portions of faults such as the San Andreas and the Cascadia megathrust. Evaluation using a test suite that spans a broader magnitude range and variety of faulting styles than has been used thus far will more fully characterize the situations in which geodetic data will make the greatest impact on EEW.

Independent testing of the three real-time geodetic algorithms described in this article has guided methodological improvements and demonstrated sufficiently good performance to warrant their further development for use in ShakeAlert. The next step is a self-consistent assessment of each approach within the ShakeAlert system architecture using the same suite of test events. Each algorithm will be evaluated against the same metrics to quantify the improvement it provides to accurate and timely ground-motion predictions for a range of source types and user-defined ground-motion thresholds. Synthetic data and high-rate GNSS data from historic earthquakes offer a means to test algorithms on large events. The results of initial testing are expected to highlight the most impactful algorithm features and guide subsequent streamlining to eliminate software components that perform redundant tasks in preparation for formal testing and certification.

Improving communications infrastructure to reduce latency and promote resilience during and after an earthquake is a priority to ensure that real-time data are received from the largest number of existing stations possible. Replacing older receivers with GNSS receivers that include onboard positioning capability could remove points of failure in the current data acquisition system. Collocation of GNSS and seismic stations presents additional opportunities to eliminate points of failure, increase network efficiency, and support a broader variety of algorithms.

\section{DATA AND RESOURCES}

Japan Meteorological Agency earthquake early warning (EEW) alerts (origin time, location, magnitude) used in Figure $1 \mathrm{ob}$ tained from http://www.eqh.dpri.kyoto-u.ac.jp/ masumi/ ecastweb/110311/index.htm (last accessed May 2018) and available at https://www.anetrt.net/anet/EEW-detail/20110311144640 (last accessed May 2018). Modified Mercalli intensity (MMI) at the station locations plotted in Figure 1 were calculated using data from KiK-net (http://www.kyoshin.bosai.go.jp, last accessed May 2018). Information regarding the Earthworm software may be obtained at http://www.isti.com/products/earthworm (last accessed April 2018). Information regarding geoJSON may be found at http://geojson.org (last accessed April 2018). Information regarding Global Navigation Satellite System (GNSS) networks that supply data to ShakeAlert and partner institutions may be found at http://seismo.berkeley.edu/bard (BARD network operated by University of California, Berkeley; last accessed May 2018), http://www.geodesy.cwu.edu (Pacific Northwest Geodetic Array [PANGA] network operated by Central Washington University; last accessed May 2018), https://www.unavco.org/projects/major-projects/pbo/pbo.html (Plate Boundary Observatory [PBO] network operated by UNAVCO Inc.; last accessed May 2018), and https:// earthquake.usgs.gov/monitoring/deformation (U.S. Geological Survey [USGS] Earthquake Science Center networks; last accessed May 2018). Some plots were made using the Generic Mapping Tools v.4.5.6 (www.soest.hawaii.edu/gmt, last accessed May 2018; Wessel and Smith, 1998).

\section{ACKNOWLEDGMENTS}

The authors wish to thank Brad Aagaard, Annemarie Baltay, and two anonymous referees for thorough reviews, as well as Elizabeth Cochran and Monica Kohler for valuable comments, all of which strengthened the article. Partial support for the development of geodetic algorithms and real-time Global Navigation Satellite System (GNSS) networks has been provided by the Gordon and Betty Moore Foundation, the Amazon Catalyst program, and the U.S. Geological Survey (USGS) Earthquake Hazards Program. Any use of trade, firm, or product names is for descriptive purposes only and does not imply endorsement by the U.S. government.

\section{REFERENCES}

Aagaard, B. T., R. W. Graves, A. Rodgers, T. M. Brocher, R. W. Simpson, D. Dreger, N. A. Petersson, S. C. Larsen, S. Ma, and R. C. Jachens (2010). Ground motion modeling of Hayward fault scenario earthquakes, part II: Simulation of long-period and broadband ground motions, Bull. Seismol. Soc. Am. 100, no. 6, 2945-2977, doi: 10.1785/0120090379.

Aagaard, B. T., R. W. Graves, D. P. Schwartz, D. A. Ponce, and R. W. Graymer (2010). Ground-motion modeling of Hayward fault scenario earthquakes, part I: Construction of the suite of scenarios, Bull. Seismol. Soc. Am. 100, no. 6, 2927-2944, doi: 10.1785/0120090324.

Allen, R. M., and A. Ziv (2011). Application of real-time GPS to earthquake early warning, Geophys. Res. Lett. 38, L16310, doi: 10.1029/ 2011 GL047947.

Atwater, B. F., and G. B. Griggs (2012). Deep-sea turbidites as guides to Holocene earthquake history at the Cascadia subduction zoneAlternative views for a seismic-hazard workshop, U.S. Geol. Surv. Open-File Rept. 2012-1043, 58 pp.

Atwater, B. F., and E. Hemphill-Haley (1997). Recurrence intervals for great earthquakes of the past 3500 years at northeastern Willapa Bay, Washington, U.S. Geol. Surv. Profess. Pap. 1576, 108 pp.

Benedetti, E., M. Branzanti, L. Biagi, G. Colosimo, A. Mazzoni, and M. Crespi (2014). Global navigation satellite systems seismology for the 
$2012 M_{\mathrm{w}} 6.1$ Emilia earthquake: Exploiting the VADASE algorithm, Seismol. Res. Lett. 85, no. 3, 649-656, doi: 10.1785/0220130094.

Bock, Y., and D. Melgar (2016). Physical applications of GPS geodesy: A review, Rep. Progr. Phys. 79, 106801, doi: 10.1088/0034-4885/79/ $10 / 106801$.

Bock, Y., D. Melgar, and B. W. Crowell (2011). Real-time strong-motion broadband displacements from collocated GPS and accelerometers, Bull. Seismol. Soc. Am. 101, no. 6, 2904-2925, doi: 10.1785/ 0120110007.

Boore, D. M. (2001). Effect of baseline corrections on displacements and response spectra for several recordings of the 1999 Chi-Chi, Taiwan, earthquake, Bull. Seismol. Soc. Am. 91, 1199-1211, doi: 10.1785/ 0120000703.

Boore, D. M., and G. M. Atkinson (2008). Ground-motion prediction equations for the average horizontal component of PGA, PGV, and 5\%-damped PSA at spectral periods between $0.01 \mathrm{~s}$ and $10.0 \mathrm{~s}$, Earthq. Spectra 24, no. 1, 99-138, doi: 10.1193/1.2830434.

Böse, M., R. Allen, H. Brown, G. Gua, M. Fischer, E. Hauksson, T. Heaton, M. Hellweg, M. Liukis, D. Neuhauser, et al. (2014). CISN ShakeAlert: An earthquake early warning demonstration system for California, in Early Warning for Geological Disasters-Scientific Methods and Current Practice, F. Wenzel and J. Zschau (Editors), Springer-Verlag Berlin Heidelberg, New York, New York, 49-69, doi: 10.1007/978-3-642-12233-0.

Böse, M., C. Felizardo, and T. H. Heaton (2015). Finite-fault rupture detector (FinDer): Going real-time in Californian ShakeAlert warning system, Seismol. Res. Lett. 86, no. 6, 1692-1704, doi: 10.1785/ 0220150154.

Böse, M., E. Hauksson, K. Solanki, H. Kanamori, Y. M. Wu, and T. H. Heaton (2009). A new trigger criterion for improved real-time performance of onsite earthquake early warning in southern California, Bull. Seismol. Soc. Am. 99, no. 2A, 897-905, doi: 10.1785/ 0120080034.

Böse, M., D. E. Smith, C. Felizardo, M.-A. Meier, T. H. Heaton, and J. F. Clinton (2018). FinDer v.2: Improved real-time ground-motion predictions for M2-M9 with seismic finite-source characterization, Geophys. J. Int. 212, no. 1, 725-742, doi: 10.1093/gji/ggx430.

Chen, D. Y., N. C. Hsiao, and Y. M. Wu (2015). The Earthworm based earthquake alarm reporting system in Taiwan, Bull. Seismol. Soc. Am. 105, 568-579, doi: 10.1785/0120140147.

Clayton, R. W., T. Heaton, M. Chandy, A. Krause, M. Kohler, J. Bunn, R. Guy, M. Olson, M. Faulkner, M. H. Cheng, et al. (2011). Community Seismic Network, Ann. Geophys. 54, no. 6, 738747, doi: 10.4401/ag-5269.

Cochran, E. S., M. D. Kohler, D. D. Given, S. Guiwits, J. Andrews, M.-A. Meier, M. Ahmad, I. Henson, R. Hartog, and D. Smith (2017). Earthquake early warning ShakeAlert system: Testing and certification platform, Seismol. Res. Lett. 89, no. 1, 108-117, doi: 10.1785/ 0220170138.

Cochran, E. S., J. Lawrence, C. Christensen, and R. Jakka (2009). The Quake-Catcher Network: Citizen science expanding seismic horizons, Seismol. Res. Lett. 80, no. 1, 26-30, doi: 10.1785/ gssrl.80.1.26.

Colombelli, S., R. M. Allen, and A. Zollo (2013). Application of real-time GPS to earthquake early warning in subduction and strike-slip environments, J. Geophys. Res. 118, 3448-3461, doi: 10.1002/ jgrb.50242.

Colosimo, G., M. Crespi, and A. Mazzoni (2011). Real-time GPS seismology with a stand-alone receiver: A preliminary feasibility demonstration, J. Geophys. Res. 116, no. B11302, doi: 10.1029/ 2010JB007941.

Crowell, B. W., D. Melgar, Y. Bock, J. S. Haase, and J. Geng (2013). Earthquake magnitude scaling using seismogeodetic data, Geophys. Res. Lett. 40, 6089-6094, doi: 10.1002/2013GL058391.

Crowell, B. W., D. Melgar, and J. Geng (2018). Hypothetical real-time GNSS modeling of the $2016 M_{\mathrm{w}} 7.8$ Kaikōura earthquake: Perspectives from ground motion and tsunami inundation prediction, Bull. Seismol. Soc. Am. 108, no. 3B, doi: 10.1785/0120170247.
Crowell, B. W., D. A. Schmidt, P. Bodin, J. E. Vidale, B. Baker, S. Barrientos, and J. Geng (2018). G-FAST earthquake early warning potential for great earthquakes in Chile, Seismol. Res. Lett. 89, 542-556, doi: 10.1785/0220170180.

Crowell, B. W., D. A. Schmidt, P. Bodin, J. E. Vidale, J. Gomberg, J. R. Hartog, V. C. Kress, T. I. Melbourne, M. Santillan, S. E. Minson, et al. (2016). Demonstration of the Cascadia G-FAST geodetic earthquake early warning system for the Nisqually, Washington, earthquake, Seismol. Res. Lett. 87, no. 4, 930-943, doi: 10.1785/ 0220150255.

Dreger, D., and A. Kaverina (2000). Seismic remote sensing for the earthquake source process and near-source strong shaking: A case study of the October 16, 1999 Hector Mine earthquake, Geophys. Res. Lett. 27, no. 13, 1941-1944.

Espinosa Aranda, J. M., A. Cuellar, G. Ibarrola, A. Garcia, S. Maldonado, and F. H. Rodriguez (2009). Evolution of the Mexican Seismic Alert System (SASMEX), Seismol. Res. Lett. 80, 694-706, doi: 10.1785/ gssrl.80.5.694.

Given, D. D., E. S. Cochran, T. Heaton, E. Hauksson, R. Allen, P. Hellweg, J. Vidale, and P. Bodin (2014). Technical implementation plan for the ShakeAlert production system-An Earthquake Early Warning system for the west coast of the United States, U.S. Geol. Surv. Open-File Rept. 2014-1097, 25 pp., doi: 10.3133/ofr20141097.

Goldberg, D. E., and Y. Bock (2017). Self-contained local broadband seismogeodetic early warning system: Detection and location, $J$. Geophys. Res. 122, 3197-3220, doi: 10.1002/2016JB013766.

Goldfinger, C., C. H. Nelson, A. E. Morey, J. E. Johnson, J. R. Patton, E. Karabanov, J. Gutiérrez-Pastor, A. T. Eriksson, E. Gràcia, G. Dunhill, et al. (2012). Turbidite event history-Methods and implications for Holocene paleoseismicity of the Cascadia subduction zone, U.S. Geol. Surv. Profess. Pap. 1661-F, 170 pp.

Grapenthin, R., I. A. Johanson, and R. M. Allen (2014a). Operational real-time GPS-enhanced earthquake early warning, J. Geophys. Res. 119, 7944-7965, doi: 10.1002/2014JB011400.

Grapenthin, R., I. A. Johanson, and R. M. Allen (2014b). The 2014 $M_{\mathrm{w}} 6.0$ Napa earthquake, California: Observations from real-time GPS-enhanced earthquake early warning, Geophys. Res. Lett. 41, 8269-8276, doi: 10.1002/2014GL061923.

Grapenthin, R., M. West, and J. Freymueller (2017). The utility of GNSS for earthquake early warning in regions with sparse seismic networks, Bull. Seismol. Soc. Am. 107, no. 4, 1883-1890, doi: 10.1785/0120160317.

Grapenthin, R., M. West, C. Tape, M. Gardine, and J. Freymueller (2018). Single-frequency instantaneous GNSS velocities resolve dynamic ground motion of the $2016 M_{\mathrm{w}} 7.1$ Iniskin earthquake, Alaska, Seismol. Res. Lett. 89, no. 3, 1040-1048, doi: 10.1785/ 0220170235.

Gregor, N., N. A. Abrahamson, G. M. Atkinson, D. M. Boore, Y. Bozorgnia, K. W. Campbell, B. S.-J. Chiou, I. M. Idriss, R. Kamai, E. Seyhan, et al. (2014). Comparison of NGA-West2 GMPEs, Earthq. Spectra 30, no. 3, 1179-1197, doi: 10.1193/070113EQS186M.

Hamling, I. J., S. Hreinsdóttir, K. Clark, J. Elliott, C. Liang, E. Fielding, N. Litchfield, P. Villamor, L. Wallace, T. J. Wright, et al. (2017). Complex multifault rupture during the $2016 M_{\mathrm{w}} 7.8$ Kaikoura earthquake, New Zealand, Science 356, 154, doi: 10.1126/science.aam7194.

Hoshiba, M., and T. Ozaki (2014). Earthquake early warning and tsunami warning of the Japan Meteorological Agency, and their performance in the 2011 off the Pacific Coast of Tohoku earthquake $\left(M_{\mathrm{w}} 9.0\right)$, in Early Warning for Geological Disasters, F. Wenzel and J. Zschau (Editors), Springer, Berlin, Germany, 1-28.

Hoshiba, M., O. Kamigaichi, M. Saito, S. Tsukada, and N. Hamada (2008). Earthquake early warning starts nationwide in Japan, Eos Trans. AGU 89, 73-74, doi: 10.1029/2008EO080001.

Hreinsdottir, S., J. T. Freymueller, R. Bürgmann, and J. Mitchell (2006). Coseismic deformation of the 2002 Denali fault earthquake: Insights from GPS measurements, J. Geophys. Res. 111, no. B03308, doi: $10.1029 / 2005$ JB003676. 
Joyner, W. B., and D. M. Boore (1981). Peak horizontal acceleration and velocity from strong-motion records including records from the 1979 Imperial Valley, California, earthquake, Bull. Seismol. Soc. Am. 71, 2011-2038.

Kodera, Y., Y. Yamada, K. Hirano, K. Tamaribuchi, S. Adachi, N. Hayashimoto, M. Morimoto, M. Nakamura, and M. Hoshiba (2018). The Propagation of Local Undamped Motion (PLUM) method: A simple and robust seismic wavefield estimation approach for earthquake early warning, Bull. Seismol. Soc. Am. 108, no. 2 , 983-1003, doi: 10.1785/0120170085.

Kohler, M. D., E. S. Cochran, D. Given, S. Guiwits, D. Neuhauser, I. Henson, R. Hartog, P. Bodin, V. Kress, S. Thompson, et al. (2017). Earthquake early warning ShakeAlert system: West coast wide production prototype, Seismol. Res. Lett. 89, no. 1, 99-107, doi: 10.1785/0220170140.

Kong, Q., R. M. Allen, L. Schreier, and Y.-W. Kwon (2016). MyShake: A smartphone seismic network for earthquake early warning and beyond, $S c i$. $A d v$. 2, no. 2, e1501055, doi: 10.1126/sciadv.1501055.

Kuyuk, H. S., and R. M. Allen (2013). A global approach to provide magnitude estimates for earthquake early warning alerts, Geophys. Res. Lett. 40, 6329-6333, doi: 10.1002/2013GL058580.

Kuyuk, H. S., R. M. Allen, H. Brown, M. Hellweg, I. Henson, and D. Neuhauser (2014). Designing a network-based earthquake early warning algorithm for California: ElarmS-2, Bull. Seismol. Soc. Am. 104, no. 1, 162-173, doi: 10.1785/0120130146.

Langbein, J., and Y. Bock (2004). High-rate real-time GPS network at Parkfield: Utility for detecting fault slip and seismic displacements, Geophys. Res. Lett. 31, L15S20, doi: 10.1029/2003GL019408.

Meier, M.-A. (2017). How good are real-time ground motion predictions from earthquake early warning systems?, J. Geophys. Res. 122, 5561-5577, doi: 10.1002/2017JB014025.

Melgar, D., and G. P. Hayes (2017). Systematic observations of the slip pulse properties of large earthquake ruptures, Geophys. Res. Lett. 44, 9691-9698, doi: 10.1002/2017GL074916.

Melgar, D., Y. Bock, and B. W. Crowell (2012). Real-time centroid moment tensor determination for large earthquakes from local and regional displacement records, Geophys. J. Int. 188, 703-718, doi: 10.1111/j.1365-246X.2011.05297.x.

Melgar, D., Y. Bock, D. Sanchez, and B. W. Crowell (2013). On robust and reliable automated baseline corrections for strong motion seismology, J. Geophys. Res. 118, 1177-1187, doi: 10.1002/ jgrb.50135.

Melgar, D., B. W. Crowell, J. Geng, R. M. Allen, Y. Bock, S. Riquelme, E. M. Hill, M. Protti, and A. Ganas (2015). Earthquake magnitude calculation without saturation from the scaling of peak ground displacement, Geophys. Res. Lett. 42, 5197-5205, doi: 10.1002/ 2015GL064278.

Melgar, D., J. Geng, B. W. Crowell, J. S. Haase, Y. Bock, W. C. Hammond, and R. M. Allen (2015). Seismogeodesy of the $2014 \mathrm{M}_{\mathrm{w}} 6.1$ Napa earthquake, California: Rapid response and modeling of fast rupture on a dipping strike-slip fault, J. Geophys. Res. 120, 50135033, doi: 10.1002/2015JB011921.

Melgar, D., R. J. LeVeque, D. S. Dreger, and R. M. Allen (2016). Kinematic rupture scenarios and synthetic displacement data: An example application to the Cascadia subduction zone, J. Geophys. Res. 121, 6658-6674, doi: 10.1002/2016JB013314.

Meng, L., J.-P. Ampuero, J. Stock, Z. Duputel, Y. Luo, and V. C. Tsai (2012). Earthquake in a maze: Compressional rupture branching during the $2012 \mathrm{M}_{\mathrm{w}} 8.6$ Sumatra earthquake, Science 337, 724726, doi: $10.1126 /$ science. 1224030 .

Minson, S. E., B. A. Brooks, C. L. Glennie, J. R. Murray, J. O. Langbein, S. E. Owen, T. H. Heaton, R. A. Iannucci, and D. L. Hauser (2015). Crowdsourced earthquake early warning, Sci. $A d v$. 1, no. 3, e1500036, doi: 10.1126/sciadv.1500036.

Minson, S. E., M.-A. Meier, A. S. Baltay, T. C. Hanks, and E. S. Cochran (2018). The limits of earthquake early warning: Timeliness of ground motion estimates, Sci. $A d v$. 4, no. 3, eaaq0504, doi: 10.1126/sciadv.aaq0504.
Minson, S. E., J. R. Murray, J. O. Langbein, and J. S. Gomberg (2014). Real-time inversions for finite fault slip models and rupture geometry based on high-rate GPS data, J. Geophys. Res. 119, no. 4, 3201-3231, doi: 10.1002/2013JB010622.

Minson, S. E., S. Wu, J. L. Beck, and T. H. Heaton (2017). Combining multiple earthquake models in real time for earthquake early warning, Bull. Seismol. Soc. Am. 107, no. 4, 1868-1882, doi: $10.1785 / 0120160331$.

Okada, Y. (1985). Surface deformation due to shear and tensile faults in a half-space, Bull. Seismol. Soc. Am. 75, no. 4, 1135-1154.

Rodgers, A. J., A. Pitarka, N. A. Petersson, B. Sjögreen, and D. B. McCallen (2018). Broadband $(0-4 \mathrm{~Hz})$ ground motions for a magnitude 7.0 Hayward fault earthquake with three-dimensional structure and topography, Geophys. Res. Lett. 45, 739-747, doi: 10.1002/2017GL076505.

Ruhl, C. J., D. Melgar, A. Chung, R. Grapenthin, and R. Allen (2018). Performance of seismic and geodetic earthquake early warnings for a suite of large earthquakes worldwide: Rapid forecasts of ground motion, Seismol. Res. Lett. 89, no. 2B, 847, doi: 10.1785/ 0220180082.

Ruhl, C. J., D. Melgar, R. Grapenthin, and R. M. Allen (2017). The value of real-time GNSS to earthquake early warning, Geophys. Res. Lett. 44, 8311-8319, doi: 10.1002/2017GL074502.

Satake, K., K. Wang, and B. F. Atwater (2003). Fault slip and seismic moment of the 1700 Cascadia earthquake inferred from Japanese tsunami descriptions, J. Geophys. Res. 108, no. B11, 1177-1187, doi: 10.1029/2003JB002521.

Si, H., and S. Midorikawa (2000). New attenuation relations for peak ground acceleration and velocity considering effects of faults type and site condition, Proc. on 12th World Conf. of Earthquake Engineering New Zealand Society for Earthquake Engineering, Upper Hutt, New Zealand, paper 0532.

Song, S. G., G. C. Beroza, and P. Segall (2008). A unified source model for the 1906 San Francisco earthquake, Bull. Seismol. Soc. Am. 98, no. 2, 823-831, doi: 10.1785/0120060402.

Stough, T., and D. S. Green (2016). Collaborative demonstration for GNSS-augmented tsunami early warnings, presented at the 2016 Fall Meeting, $A G U$, San Francisco, California, 12-16 December, Abstract G44A-03.

U.S. Geological Survey (USGS) (2017). Advanced National Seismic System-Current status, development opportunities, and priorities for 2017-2027, U.S. Geological Survey Circular 1429, 32 pp., doi: $10.3133 /$ cir1429.

Wells, D. L., and K. J. Coppersmith (1994). New empirical relationships among magnitude, rupture length, rupture width, rupture area, and surface displacement, Bull. Seismol. Soc. Am. 84, no. 4, 9741002.

Wessel, P., and W. H. F. Smith (1998). New, improved version of the Generic Mapping Tools released, Eos Trans. AGU 79, 579.

Zielke, O., J. R. Arrowsmith, L. G. Ludwig, and S. O. Akciz (2012). High-resolution topography-derived offsets along the 1857 Fort Tejon earthquake rupture trace, San Andreas fault, Bull. Seismol. Soc. Am. 102, no. 3, 1135-1154, doi: 10.1785/0120110230.

J. R. Murray

J. O. Langbein

S. E. Minson

U.S. Geological Survey

345 Middlefield Road, MS 977

Menlo Park, California 94025 U.S.A.

jrmurray@usgs.gov

B. W. Crowell

D. A. Schmidt

Department of Earth and Space Sciences 
University of Washington

Johnson Hall Room-070, Box 351310 4000 15th Avenue NE

Seattle, Washington 98195 U.S.A.

R. Grapenthin

Department of Earth \& Environmental Science

New Mexico Tech

801 Leroy Place

Socorro, New Mexico 87801 U.S.A.

K. Hodgkinson

UNAVCO Inc.

1206 North Drive

Socorro, New Mexico 87801 U.S.A.
T. Melbourne

Department of Geological Sciences Central Washington University 400 East University Way Ellensburg, Washington 98926 U.S.A.

$$
\begin{array}{r}
\text { D. Melgar' } \\
\text { Department of Earth and Planetary Science } \\
\text { University of California } \\
307 \text { McCone Hall } \\
\text { Berkeley, California } 94720 \text { U.S.A. }
\end{array}
$$

Published Online 3 October 2018

${ }^{1}$ Now at Department of Earth Sciences, University of Oregon, 100 Cascade Hall, 1272 University of Oregon, Eugene, Oregon 97403 U.S.A. 